OPEN ACCESS

Edited by:

Carmen Castro Canavier, Louisiana State University,

United States

Reviewed by:

Zayd Khaliq,

National Institute of Neurological

Disorders and Stroke (NINDS),

United States

*Correspondence:

Vincent Seutin

v.seutin@uliege.be

Specialty section:

This article was submitted to

Cellular Neurophysiology

a section of the journal

Frontiers in Cellular Neuroscience

Received: 26 May 2021

Accepted: 19 July 2021

Published: 13 August 2021

Citation:

Seutin V (2021) Electrophysiological

Quality Control of Human

Dopaminergic Neurons: Are We Doing

Enough?

Front. Cell. Neurosci. 15:715273.

doi: 10.3389/fncel.2021.715273

\section{Electrophysiological Quality Control of Human Dopaminergic Neurons: Are We Doing Enough?}

\author{
Vincent Seutin* \\ Laboratory of Neurophysiology, GIGA Neurosciences, Liège University, Liège, Belgium
}

Keywords: dopaminergic neurons, Parkinson's disease, cell transplantation, excitability, human induced pluripotent stem cells

\section{INTRODUCTION}

The breakthrough of induced pluripotent stem (iPS) cell technology (Takahashi and Yamanaka, 2006) has allowed scientists to design protocols allowing the differentiation of these cells into the main cell types of our organism. This possibility is particularly exciting in the field of Parkinson's disease (PD), since early experiments using heterologous dopaminergic (DA) or chromaffin cells have demonstrated the ability of such cells, when injected in adequate sites, to improve symptoms of the disease in a sustained manner (Kefalopoulou et al., 2014). The possibility of reproducing this effect using autologous cells, thereby free of ethical concerns, is of course fascinating (Barker et al., 2017; Parmar et al., 2020). It has clearly been demonstrated that symptoms of experimental parkinsonism can be relieved in several species by such grafts (Kikuchi et al., 2017; Song et al., 2020), with a first human case report study yielding encouraging results (Schweitzer et al., 2020). Protocols are being refined to improve the yield of DA neurons and minimize the survival of undifferentiated cells (e.g., Piao et al., 2021). Immunohistochemical methods allow to clearly define the presence of DA neurons, the absence of other monoaminergic neurons (e.g., serotoninergic neurons) and the molecular subtype of these DA neurons (by examining the expression of a variety of transcription factors such as NURR1, PITX3, etc...). Many experiments have confirmed the possibility of obtaining preparations devoid of oncogenic potential.

In the published papers, some efforts have been made to characterize the physiological properties of the DA neurons, but I argue that, in many cases, the data is not completely convincing and, more importantly, that the reader has no idea of the percentage of neurons that display the specific properties of these neurons. I believe that more standardization of these experiments is important to assess the functional quality of the future grafts. Although I reckon that safety is of paramount importance, I also believe that suboptimal functionality may impair the clinical effectiveness of future procedures.

\section{FUNCTIONAL CHARACTERIZATION OF DOPAMINERGIC NEURONS IN THE PUBLISHED LITERATURE}

It should be first emphasized that we do not know anything about the physiological activity of DA neurons in situ in the human brain (but see below). From the rodent literature, identified DA neurons from the substantia nigra, pars compacta (SNc) have several cardinal features: (1) they have the ability to fire action potentials spontaneously at a low frequency $(0.5-5 \mathrm{~Hz})$ both in vitro (e.g., dissociated DA neurons: Puopolo et al., 2007) and ex vivo in rodent brain slices (numerous studies). This slow endogenous pacemaking is very important. Indeed, $\ll$ in their tonic mode, DA neurons maintain a steady, baseline level of dopamine in downstream neural structures that 
is vital for enabling the normal functions of neural circuits $\gg$ (Bromberg-Martin et al., 2010). More specifically, a minimal activation of post-synaptic receptors is probably critical to ensure their appropriate sensitivity. The pacemaking activity is exquisitely regular, with the coefficient of variation $(\mathrm{CV})$ of interspike intervals (ISI) usually below 0.1 (CV $=$ standard deviation of the ISI's/Mean ISI) (de Vrind et al., 2016). (2) When examined under voltage clamp conditions, SNc DA neurons express the $\mathrm{I}_{\mathrm{h}}$ current, which has a characteristic slow activation (Franz et al., 2000), as compared e.g., to hippocampal CA1 neurons. This current is a real hallmark and allows us to clearly distinguish DA neurons from GABAergic neurons in rodent slices (see also below). (3) In addition, the firing of DA neurons is normally controlled by somato-dendritic D2-type receptors. Activation of these receptors by dendritically released dopamine leads to a hyperpolarization mediated by GIRKtype $\mathrm{K}^{+}$channels. This auto-inhibition may be functionally important in these neurons. (4) Some other characteristics can be observed, such as an $\mathrm{I}_{\mathrm{A}}$ type $\mathrm{K}^{+}$current, a medium duration after hyperpolarization mediated by SK3 channels, etc... However, these features are less characteristic of the "DA phenotype".

In addition, in vivo, DA neurons can switch to burst firing and this mode induces a larger increase in synaptic and perisynaptic dopamine concentration. We and others have shown that NMDA receptor activation and down-regulation of the SK current are critical for bursting to be fully expressed (Johnson et al., 1992; Waroux et al., 2005, Zweifel et al., 2009; Soden et al., 2013). This firing pattern is critical because it usually is considered as a "GO" signal (Bromberg-Martin et al., 2010).

When recording from presumed human DA neurons a few years ago, we were struck by the similarities between the firing of some of these cells and rodent DA neurons (Borgs et al., 2016). Criteria 1-3 above were clearly satisfied in some neurons. This suggests that the physiology of in situ DA neurons in the human brain is similar to that of rodent cells. The more recent literature tends to confirm this assumption. Table $\mathbf{1}$ summarizes the electrophysiological characterization that was performed in recent papers describing the properties of human DA neuron preparations. In several cases, the amount of information is limited and, perhaps more importantly, the reader has no idea on whether the physiological properties were reproducible from batch to batch. One can clearly see that the information provided is limited (the second column starting from the left actually simply shows that the cells are excitable). In several cases, some of the physiological hallmarks of DA neurons have not been demonstrated to be present. Note that, in several of these studies, additional experiments showed that DA release can be measured from the cell preparations. However, given the harsh protocols used to evoke such release, this type of experiment does not guarantee that DA would be released physiologically. One other information that is usually missing is the temperature at which the experiments are carried out. This is a significant problem because pacemaking of these neurons is very temperaturedependent (Guatteo et al., 2005). Finally, a critical piece of information which is also missing is whether one or more than one batch of derived DA neurons was tested.

\section{A PROPOSAL FOR FUTURE GUIDELINES}

From the data reviewed above, I propose the following standardized guidelines to assess the cell physiology of human DA cell preparations in future studies:

All the criteria below should be satisfied in at least 3 human iPS cell-derived DA neuron preparations made during different differentiations.

Temperature of the experiments should be close to physiological $\left(32-35^{\circ} \mathrm{C}\right)$. The composition of the extracellular solution could be as follows: $140 \mathrm{mM} \mathrm{NaCl}, 5 \mathrm{mM} \mathrm{KCl}$, $2 \mathrm{mM} \mathrm{CaCl}_{2}, 2 \mathrm{mM} \mathrm{MgCl}, 15 \mathrm{mM} \mathrm{HEPES}$ and $10 \mathrm{mM} \mathrm{D}$ glucose; $\mathrm{pH}$ 7.4. The intrapipette solution could be as follows: $140 \mathrm{mM}$ KGluconate or Kmethylsulphate, $10 \mathrm{mM} \mathrm{NaCl}, 0.5 \mathrm{mM}$ $\mathrm{CaCl}_{2}, 15$ mM HEPES, 2 mM ATP-Mg, 5 mM EGTA; pH 7.4. Kmethylsulphate is preferred in general because gluconate tends to inhibit the SK-mediated conductance. Small variations around these values are of course possible, but I recommend to use a HEPES-based extracellular solution, which is appropriate for isolated cells.

- Slow spontaneous pacemaking between 0.5 and $4 \mathrm{~Hz}$ with a $\mathrm{CV}<0.2(N=6$ cells $)$.

- Robust $\mathrm{I}_{\mathrm{h}}$ current : as measured in voltage clamp using a pulse protocol from -60 to $-120 \mathrm{mV}$, current amplitude should be $\geq 50 \mathrm{pA}(N=6$ cells $)$

- Complete and reversible inhibition of firing (or outward current $>30 \mathrm{pA}$ in voltage clamp at $-60 \mathrm{mV})$ by $100 \mu \mathrm{M}$ dopamine $(N=6$ cells $)$

Criteria 1,2 and 3 may be assessed in the same cells or in different cells. The number of experiments proposed is not based on any power calculation, but on common sense.

\section{DISCUSSION}

The perspective of improving the lives of parkinsonian patients in the future with autologous grafts of "their" DA neurons is very uplifting. However, in order to make it a reality, we as a community need to ensure that all aspects of the grafting procedure are optimal. I strongly believe that the physiological aspect described here is important if we are to guarantee effective grafts to the patients. We are still in a very preliminary phase in this field and it is time to standardize as much as possible the preparations. I believe that fulfilling the above criteria ensures one aspect of the standardization. One may argue that some of these criteria are not essential. For example, we cannot be sure to which extent the autoinhibition by D2 somatodendritic autoreceptors would be critical to the function of DA neurons once they are grafted. However, work in rodents demonstrates the need for DA neurotransmission to be regulated by D2 autoreceptors, which are "short" D2 (D2S) receptors. Thus specific deletion of $\mathrm{D} 2 \mathrm{~S}$ receptors disrupts the classical behavioral effect of low dose D2 agonists, as well as the regulation of tyrosine hydroxylase (TH) phosphorylation (Radl et al., 2018). Therefore, important aspects of both the biochemistry and functionality of DA neurons are dependent upon correct autoreceptor function. 
TABLE 1 | Summary of electrophysiological hallmarks of nigral dopaminergic neurons demonstrated to be present in engineered iPS cell-derived human DA cells.

\begin{tabular}{|c|c|c|c|c|c|c|}
\hline Study & $\begin{array}{l}\text { Ability to fire APs } \\
\text { upon I injection }\end{array}$ & $\begin{array}{l}\text { Spontaneous slow(< } \\
5 \mathrm{~Hz}) \text { pacemaking }\end{array}$ & $\begin{array}{l}\text { Presence of } I_{h} \\
\text { (CC or VC) }\end{array}$ & $\begin{array}{l}\text { Hyperpolarization } \\
\text { by D2 agonist }\end{array}$ & Other & Remark \\
\hline Borgs et al. (2016) & Yes (11 cells) & Yes ( 3 cells) & Yes (3 cells) & Yes ( 3 cells) & - & $\begin{array}{l}\text { Some properties were } \\
\text { time-dependent }\end{array}$ \\
\hline Kikuchi et al. (2017) & Yes (4 cells) & No & No & Not tested & & \\
\hline Song et al. (2020) & Yes (7 cells) & Yes (4 cells) & $\begin{array}{l}\text { No (seems actually } \\
\text { absent: suppl Fig. } \\
\text { 10A) }\end{array}$ & Not tested & $\begin{array}{l}\text { Population activity } \\
\text { reported }\end{array}$ & \\
\hline Kim et al. (2021) & Yes (?) & $\begin{array}{l}\text { Yes }^{\circ}(8,10 \text { and } 14 \text { cells at } \\
40,60 \text { and } 75 \text { DIV })\end{array}$ & Yes (?) & Not tested & $\begin{array}{l}\text { Developmental aspect } \\
\text { of action potential } \\
\text { duration and input } \\
\text { resistance shown } \\
\text { M current suggested }\end{array}$ & $\begin{array}{l}\text { Some properties were } \\
\text { time-dependent }\end{array}$ \\
\hline Doi et al. (2020) & Yes (16 out of 18 cells) & $\begin{array}{l}\text { Yes* ( } 12 \text { out of } 18 \text { cells in } \\
\text { two experiments) }\end{array}$ & No & Not tested & & \\
\hline
\end{tabular}

? Means that the number of cells tested was not reported.

- The spontaneous firing shown in their figure $3 \mathrm{M}$ is atypical in the sense that it is quite irregular.

*The firing rate of the cell which was shown was $7 \mathrm{~Hz}$.

In addition, slow $\mathrm{I}_{\mathrm{h}}$ currents of the type expressed in DA neurons are thought to be important in synaptic integration. We and others have demonstrated that, when present, the current strongly decreases temporal summation of excitatory post-synaptic potentials (EPSCs) in DA neurons (Masi et al., 2013; Engel and Seutin, 2015). When thinking about physiology, we should try to define what exactly would be the therapeutic goals of DA grafts in PD patients. Currently, about $10^{6} \mathrm{DA}$ neurons are injected in three tracks in both putamens (left and right) in humans (Schweitzer et al., 2020). What do we hope from these cells? A large fraction of them will probably degenerate and an additional pool will stop expressing $\mathrm{TH}$ : indeed $\mathrm{TH}$ expression was observed in about $30 \%$ of surviving cells in a monkey study (Kikuchi et al., 2017). Experimental observations and calculations suggest that around $10^{5}$ cells per track would be largely enough to support recovery in humans (see a discussion about this point in Kikuchi et al., 2017). There is evidence, both from older studies using heterologous neurons in human patients and from recent preclinical studies using iPS-derived DA neurons, that the DA neurons within the graft extend their dendrites in the host tissue, become innervated and innervate targets (Kriks et al., 2011; Grealish et al., 2015). Actually, it was even shown that the Lewy body pathology can spread from the host tissue to grafted cells (Li et al., 2008). Ideally, grafted DA neurons should release low amounts of dopamine in their striatal microenvironment in a regular manner, mimicking their physiological activity and providing their "enabling function" to the basal ganglia circuitry. Possibly, if their progressive innervation is close to physiological (see Watabe-Uchida et al., 2012), one may envision that synaptic activation by some of their normal glutamatergic inputs would be able to induce bursting and to underlie the "GO" signal. However, this switch should occur appropriately, in order to prevent graft-induced dyskinesia's (see Parmar et al., 2020). Evidently, at the present time, we have no means to evaluate to what extent this would occur in situ. Interestingly, however, depending on the initial clinical results of the future grafts, tuning of the excitability of DA neurons could provide a means to minimize this type of problem, further emphasizing the interest of carefully evaluating this parameter.

The experiments suggested in these guidelines should of course be complemented with other experiments, in particular those aimed at determining the subtypes of SNc DA neurons that are mostly generated (Poulin et al., 2020). This will be important, because some subpopulations of SNc DA neurons, e.g., those expressing acetaldehyde dehydrogenase 1A1, appear to be more prone to neurodegeneration than others, both in rodents and humans (Poulin et al., 2020). Therefore, ensuring a high percentage of "resistant" DA neurons might be critical as well to the success of transplantation. This will also necessitate further investigations on the biology of human iPS-derived DA neurons.

\section{AUTHOR CONTRIBUTIONS}

The author confirms being the sole contributor of this work and has approved it for publication.

\section{FUNDING}

This work was funded by a grant from the Fonds National de la Recherche Scientifique (FNRS, Belgium) (contract J.0148.19) to VS.

\section{ACKNOWLEDGMENTS}

VS wishes to thank all present members of his lab for helpful discussions, and Dr. Philippe Alix who performed patch clamp recordings on human DA neurons. VS also thanks his Colleague Dr. L. Nguyen for making these recordings possible. 


\section{REFERENCES}

Barker, R. A., Parmar, M., Studer, L., and Takahashi, J. (2017). Human trials of stem cell-derived dopamine neurons for parkinson's disease: dawn of a new era. Cell Stem Cell 21, 569-573. doi: 10.1016/j.stem.2017.09.014

Borgs, L., Peyre, E., Alix, P., Hanon, K., Grobarczyk, B., Godin, J. D., et al. (2016). Dopaminergic neurons differentiating from LRRK2 G2019S induced pluripotent stem cells show early neuritic branching defects. Sci Rep. 6:33377. doi: $10.1038 /$ srep33377

Bromberg-Martin, E. S., Matsumoto, M., and Hikosaka, O. (2010). Dopamine in motivational control: rewarding, aversive, and alerting. Neuron $68,815-834$. doi: 10.1016/j.neuron.2010.11.022

de Vrind, V., Scuvée-Moreau, J., Drion, G., Hmaied, C., Philippart, F., Engel, D., et al. (2016). Interactions between calcium channels and SK channels in midbrain dopamine neurons and their impact on pacemaker regularity: contrasting roles of N- and L-type channels. Eur. J. Pharmacol.. 788, 274-279. doi: 10.1016/j.ejphar.2016.06.046

Doi, D., Magotani, H., Kikuchi, T., Ikeda, M., Hiramatsu, S., and Yoshida, K. (2020). Pre-clinical study of induced pluripotent stem cell-derived dopaminergic progenitor cells for Parkinson's disease. Nat. Commun. 11:3369. doi: 10.1038/s41467-020-17165-w

Engel, D., and Seutin, V. (2015). High dendritic expression of $\mathrm{I}_{\mathrm{h}}$ in the proximity of the axon origin controls the integrative properties of nigral dopamine neurons. J. Physiol. 593, 4905-4922. doi: 10.1113/JP271052

Franz, O., Liss, B., Neu, A., and Roeper, J. (2000). Single-cell mRNA expression of HCN1 correlates with a fast gating phenotype of hyperpolarization-activated cyclic nucleotide-gated ion channels (Ih) in central neurons. Eur. J. Neurosci. 12, 2685-2693. doi: 10.1046/j.1460-9568.2000.00151.x

Grealish, S., Heuer, A., Cardoso, T., Kirkeby, A., Jönsson, M., Johansson, J., et al. (2015). Monosynaptic tracing using modified rabies virus reveals early and extensive circuit integration of human embryonic stem cell-derived neurons. Stem Cell Rep. 4, 975-983. doi: 10.1016/j.stemcr.2015.04.011

Guatteo, E., Chung, K. K. H., Bowala, T. K., Bernardi, G., Mercuri, N. B., and Lipski, J. (2005). Temperature sensitivity of dopaminergic neurons of the substantia nigra pars compacta: involvement of transient receptor potential channels. J. Neurophysiol. 94, 3069-3080. doi: 10.1152/jn.00066.2005

Johnson, S. W., Seutin, V., and North, R. A. (1992). Burst-firing in dopamine neurons induced by N-methyl-D-aspartate: role of electrogenic sodium pump. Science 258, 665-667. doi: 10.1126/science.1329209

Kefalopoulou, Z., Politis, M., Piccini, P., Mencacci, N., Bhatia, K., and Jahanshahi, M. (2014). Long-term clinical outcome of fetal cell transplantation for Parkinson disease: two case reports. JAMA Neurol. 71, 83-87. doi: 10.1001/jamaneurol.2013.4749

Kikuchi, T., Morizane, A., Doi, D., Magotani, H., Onoe, H., and Hayashi, T. (2017). Human iPS cell-derived dopaminergic neurons function in a primate Parkinson's disease model. Nature 548, 592-596. PMID: 28858313. doi: $10.1038 /$ nature23664

Kim, T. W., Piao, J., Koo, S. Y., Kriks, S., Chung, S. Y., Betel, D., et al. (2021). Biphasic activation of WNT signaling facilitates the derivation of midbrain dopamine neurons from hESCs for translational use. Cell Stem Cell 28, 343-355. doi: 10.1016/j.stem.2021.01.005

Kriks, S., Shim, J. -W., Piao, J., Ganat, Y. M., Wakeman, D. R., Xie, Z., et al. (2011). Dopamine neurons derived from human ES cells efficiently engraft in animal models of Parkinson's disease. Nature 480, 547-551. doi: 10.1038/nature10648

Li, J. -Y., Englund, E., Holton, J. L., Soulet, D., Hagell, P., Lees, A. J., et al. (2008). Lewy bodies in grafted neurons in subjects with Parkinson's disease suggest host-to-graft disease propagation. Nat. Med. 14, 501-503. doi: 10.1038/nm1746

Masi, A., Narducci, R., Landucci, E., Moroni, F., and Mannaioni, G. (2013). $\mathrm{MPP}^{+}$-dependent inhibition of $\mathrm{I}_{\mathrm{h}}$ reduces spontaneous activity and enhances EPSP summation in nigral dopamine neurons. Br. J. Pharmacol. 169, 130-142. doi: $10.1111 /$ bph.12104
Parmar, M., Grealish, S., and Henchcliffe, C. (2020). The future of stem cell therapies for Parkinson disease. Nat. Rev. Neurosci. 21, 103-115. doi: 10.1038/s41583-019-0257-7

Piao, J., Zabierowski, S., Dubose, B. N., Hill, E. J., Navare, M., Claros, N., et al. (2021). Preclinical Efficacy and safety of a human embryonic stem cellderived midbrain dopamine progenitor product, MSK-DA01. Cell Stem Cell 28, 217-229.e7. doi: 10.1016/j.stem.2021.01.004

Poulin, J.-F., Gaertner, Z., Moreno-Ramos, O. A., and Awatrami, R. (2020). Classification of midbrain dopamine neurons using single-cell gene expression profiling approaches. Trends Neurosci. 43, 155-169. doi: 10.1016/j.tins.2020.01.004

Puopolo, M., Raviola, E., and Bean, B. P. (2007). Roles of subthreshold calcium current and sodium current in spontaneous firing of mouse midbrain dopamine neurons. J. Neurosci. 27, 645-656. doi: 10.1523/JNEUROSCI.4341-06.2007

Radl, D., Chiacchiaretta, M., Lewis, R. G., Brami-Cherrier, K., Arcuri, L., and Borrelli, E. (2018). Differential regulation of striatal motor behavior and related cellular responses by dopamine D2L and D2S isoforms. Proc. Natl. Acad. Sci. U.S.A. 115, 198-203. doi: 10.1073/pnas.1717194115

Schweitzer, J. S., Song, B., Herrington, T. M., Park, T. Y., Lee, N., Ko, S., et al. (2020). Personalized iPSC-derived dopamine progenitor cells for Parkinson's disease. N. Engl. J. Med. 382, 1926-1932. doi: 10.1056/NEJMoa1915872

Soden, M., Jones, G. L., Sanford, C. A., Chung, A. S., Güler, A. D., Chavkin, C., et al. (2013). Disruption of dopamine neuron activity pattern regulation through selective expression of a human KCNN3 mutation. Neuron 80, 997-1009 doi: 10.1016/j.neuron.2013.07.044

Song, B., Cha, Y., Ko, S., Jeon, J., Lee, N., Seo, H., et al. (2020). Human autologous iPSC-derived dopaminergic progenitors restore motor function in Parkinson's disease models. J. Clin. Invest. 130, 904-920. doi: 10.1172/JCI130767

Takahashi, K., and Yamanaka, S. (2006). Induction of pluripotent stem cells from mouse embryonic and adult fibroblast cultures by defined factors. Cell 126, 663-676. doi: 10.1016/j.cell.2006.07.024

Waroux, O., Massotte, L., Alleva, L., Graulich, A., Thomas, E., Liégeois, J. F., et al. (2005). SK channels control the firing pattern of midbrain dopaminergic neurons in vivo in the rat. Eur. J. Neurosci. 22, 3111-3121. doi: $10.1111 / j .1460-9568.2005 .04484 . x$

Watabe-Uchida, M., Zhu, L., Ogawa, S. K., Vamanrao, A., and Uchida, N. (2012). Whole-brain mapping of direct inputs to midbrain dopamine neurons. Neuron 74, 858-873. doi: 10.1016/j.neuron.2012.03.017

Zweifel, L. S., Parker, J. G., Lobb, C. J., Rainwater, A., Wall, V. Z., Fadok, J. P., et al. (2009). Disruption of NMDAR-dependent burst firing by dopamine neurons provides selective assessment of phasic dopamine-dependent behavior. Proc. Natl. Acad. Sci. U.S.A 106, 7281-7288. doi: 10.1073/pnas.0813415106

Conflict of Interest: The author declares that the research was conducted in the absence of any commercial or financial relationships that could be construed as a potential conflict of interest.

Publisher's Note: All claims expressed in this article are solely those of the authors and do not necessarily represent those of their affiliated organizations, or those of the publisher, the editors and the reviewers. Any product that may be evaluated in this article, or claim that may be made by its manufacturer, is not guaranteed or endorsed by the publisher.

Copyright (c) 2021 Seutin. This is an open-access article distributed under the terms of the Creative Commons Attribution License (CC BY). The use, distribution or reproduction in other forums is permitted, provided the original author(s) and the copyright owner(s) are credited and that the original publication in this journal is cited, in accordance with accepted academic practice. No use, distribution or reproduction is permitted which does not comply with these terms. 